\title{
Editorial
}

\section{Antibiotic Policy: An Essential, Time Demanded but Ignored Reality in Treating Infectious Diseases in Bangladesh}

Many questions are now raised by reviewing few deaths associated with severe, untreatable infections, concentrating to whether the deaths were merely due to infections or indiscriminate antibiotic usage induced failure of treatment. ${ }^{1-3}$

Antibiotics are one of the most important and valuable discoveries of modern medicine and are essential for treatments of many serious infections. But soon a link has been identified between antibiotic use or abuse and the emergence of antibiotic-resistant bacteria causing hospitalacquired infections. In the countries like Bangladesh, where all kinds of medicines, including the antibiotics, are sold over the counter, misuse of antibiotics has been found to be responsible for a pool of resistant strains of the microbes. ${ }^{4}$ Within the hospitals, the unnecessary use or overuse of antibiotics encourages the selection and proliferation of resistant strains of bacteria.

Because of increasing concern and awareness regarding antibiotic resistance problems worldwide and frequent inappropriate use of antimicrobial agents in hospitals, these drugs have often been target for restriction and controlled use. Tuberculosis, gonorrhoea, malaria, and childhood ear infections are just few examples of the diseases that have become hard to treat with antibiotic drugs. Part of this problem is that bacteria and other microorganisms that cause infections are remarkably resilient and can develop ways to survive drugs meant to kill or weaken them. This antibiotic resistance is largely due to inappropriate use of antibiotics. Unless antibiotic resistance problems are detected as they emerge, and actions are taken to contain them, world could be

\footnotetext{
Correspondence:

Dr. KM Shahidul Islam

Professor and Head, Department of Microbiology

Begum Khaleda Zia Medical College

Sher-E-Bangla Nagar, Dhaka

E-mail : kmshahid2000@yahoo.com
}

faced with previously treatable diseases that might again become untreatable, as in the days before antibiotics were developed. 5

The overuse of antibiotics has led to increasing concerns about bacterial resistance which enforced many highest level bodies of some developed countries like the United Kingdom to make special awareness committee for preparation of combating the situations.6,7 The problem of antibiotic overuse is, therefore, an international one and alarm had been expressed in the developed countries for several years, ${ }^{8}$ and Bangladesh should now address the problem within shortest possible delay to overcome ill-effects.

Indiscriminate use of antibiotics also found responsible for increasing the burden of total treatment costs in terms of treatment failure followed by reintroduction of another one /two/ three antibiotics, lengthening hospital stay, and minimizing working hours.

Increasing antimicrobial resistance and the pressures of caremanagement costs have led to increased needs to assess and ensure appropriate antimicrobial use. Restrictive formularies, antibiotic cycling, academic detailing, antibiotic order forms, and selective susceptibility reporting have been advocated and may be effective in controlling certain types of epidemic resistance. 9

Implementation of antibiotic policy might ensure appropriate use of antibiotics in clinical infections, resulting in more effective treatment of infections for a better patient outcome. In addition, antibiotic policy would contribute significantly to minimize risk of healthcare-associated infections occurring, and would provide benefits to patients and the staff for costeffective service delivery and desired clinical outcomes.

For implementation of an antibiotic policy in a healthcare facility, almost all levels of staff associated with clinical infections should be assigned with specific duties. For 
example, there should be a Committee for Hospital Infection Control (CHIC) that will ensure utilization of antibiotics appropriately with a target in optimal treatment of infections with minimal risk of healthcare-associated infections. The CHIC should be led by a Microbiologist, and include working representations from the relevant prescribing physicians. The CHIC will formulate an annual action plan for: (i) monitoring antibiotic use and changes in healthcare-associated infections in clinical areas; (ii) educating all levels of clinical staff on antibiotic consumption; and (iii) influencing antibiotic prescription by taking feedback of prescribing data, healthcare-associated infection surveillance data, and restricting antibiotic availability. The CHIC also ensure proper review of antibiotic policy guidelines annually and keeping it up-to-date. The CHIC should co-opt relevant subcommittee/ personnel for proper implementation of the antibiotic policy. A Clinical pharmacist, if available, might be assigned with responsibilities to keep and provide relevant data on antibiotic usage for individual clinical infection as well as will help in implementing the antibiotic policy and to influence antibiotic prescriptions by noticing any improper prescription to the CHIC. 5

In conclusion, the mainstay of an antibiotic policy should be: (i) to improve patient care by promoting the best practice in antibiotic prophylaxis and therapy, and make better use of resources by using cheaper drugs wherever possible; (ii) to retard the emergence and spread of multiple antibioticresistant bacteria by improving education of the related doctors by providing guidelines for appropriate therapy; and (iii) to eliminate the use of unnecessary or ineffective antibiotics and to restrict the use of expensive or the most recent highly sensitive antibiotics. ${ }^{5}$

Shahidul Islam

Professor and Head, Department of Microbiology, Begum Khaleda Zia Medical Colleges, Sher-E-Bangla Nagar, Dhaka

Md. Ashraful Alam

OSD, DGHS (Deputed to NIPSOM)

Mohakhali, Dhaka

\section{References}

1. Kollef MH, Ward S, Sherman G, et al. Inadequate treatment of nosocomial infections is associated with certain empirical antibiotic choices. Crit Care Med 2000; 28: 3456-3464.

2. Raymond DP, Pelletier SJ, Crabtree TD, et al. Impact of a rotating empirical antibiotic schedule on infectious mortality in an intensive care unit. Crit Care Med 2001; 29: 1101-1108.

3. Murthy R. Implementation of strategies to control antimicrobial resistance. Chest 2001; 119: 405S-411S.

4. International Federation of Infection Control (IFIC). Infection Control: Basic Concepts and Practices, 2nd edition. Web page retrieved from http://www.theific.org/oldsite/Manual/ABX.htm [accessed on: 22/03/08]

5. Binyon D, Cooke RPD. Restrictive antibiotic policies- how effective are they? Hosp Pharma 2000; 7 (7): 183-187.

6. House of Lords Select Committee on Science and Technology. Report: Resistance to antibiotics and other antimicrobial agents. London: Stationery Office; 1998.

7. NHS Executive. HSC 1999/049: Resistance to antibiotics and other antimicrobial agents. London: NHS Executive; 1999.

8. American Society for Microbiology. ASM task force on antimicrobial resistance. J Antimicrob Chemother 1999; 43: 459-465.

9. Burke JP. Antibiotic policy in a Hospital. Abstract published in International Science Conference of Antimicrob Agents Chemother (abstract no. 623) 1999 (September 26-29); 39: p. 755 .

10. South Tree Hospitals, NHS Trust. Antibiotic policy: Hospital infection control policy. Web page retrieved from: http//www. [accessed on 23/04/2007]

[Conflict of interest: None declared] 